\title{
La pobreza, la universidad y el oficio de arquitecto en la América latina de comienzos del siglo XXI
}

\author{
Poverty, the university, and the architect profession in Latin America \\ at the beginning of the XXI century
}

\author{
Víctor Saúl* \\ Fecha de recepción: 30-05-2017 - Fecha de aceptación: 10-09-2017 \\ Hábitat y Sociedad (ISSN 2173-125X), n. ${ }^{\circ}$ 10, noviembre de 2017, pp. 305-322. \\ http://dx.doi.org/10.12795/HabitatySociedad.2017.i10.17
}

\begin{abstract}
Among its many aims, the organization of the ArCaDia 4 Congress included paying tribute to the author and entrusting with the opening speech of the meeting. From this setting, the conference was prepared with the following structure: The first segment is intended to characterize the housing shortage situation of the low-income sectors in Latin America as a conceptual framework for their approach from social organizations, governmental or otherwise. The second segment is a signalling of the role, assumed with greater or lesser approximation, of Latin American universities as involved or implicated social organizations. The third is a proposal for a criterion of approach from social organizations to the housing crisis, based on the characterization examined in the first segment. The fourth is a synthesis of the experience and the production of the organisms created and conducted by the author within the Faculty of Architecture and Urbanism of the University of the Northeast, Argentina, and the fifth segment is a set of propositions, developed over the course of that activity, oriented towards the appropriate conception of housing access management.
\end{abstract}

\section{Key words}

Habitat; Poverty; Latin America; University; Architects, Participation; Concertation

\section{Resumen}

La organización del Congreso ArCaDia 4 incluyó entre sus propósitos rendir un homenaje al autor y encomendarle la disertación de apertura de la reunión. Desde este encuadre se elaboró la conferencia, con la siguiente estructura: el primer segmento se destina a hacer una caracterización de la situación de carencia habitacional de los sectores populares en la América latina, como andamiaje conceptual para su abordaje desde las organizaciones sociales, gubernamentales o no. El segundo segmento es un señalamiento del papel, asumido con mayor o menor aproximación, de las universidades latinoamericanas, como organizaciones sociales involucradas, o involucrables. El tercero es una propuesta de criterio de abordaje, desde las organizaciones sociales, a la crisis habitacional, a partir de la caracterización examinada en el primer segmento. El cuarto es una síntesis de la experiencia y la producción de los organismos creados y conducidos por el autor dentro de la Facultad de Arquitectura y Urbanismo de la Universidad del Nordeste, Argentina, y el quinto segmento es un conjunto de proposiciones elaboradas en el curso de esa actividad, orientadas a una concepción apropiada de la gestión del acceso a la vivienda.

\section{Pallabras clave}

Hábitat; Pobreza; Latinoamérica; Universidad; Arquitectos; Participación; Concertación

\footnotetext{
* Arquitecto. Investigador principal, jubilado, del Consejo Nacional de Investigaciones Científicas y Técnicas, CONICET, Argentina. C.e.: victorsaul1931@hotmail.com.
} 


\section{La situación de carencia habitacional de los sectores populares en la América latina ${ }^{1}$}

La necesidad de gran parte de la población de la América latina de disponer de un hábitat doméstico satisfactorio y compatible con las pautas de la estructura social vigente, presenta fuertes y claros rasgos de una situación de: masividad, criticidad y urgencia.

No se trata de señalamientos destinados a conmover, o a inducir acciones precipitadas de salvataje o de beneficencia efímera. Estos rasgos se proponen como indicadores objetivos que sería imprescindible adoptar como base de trabajo al diseñar e implementar estrategias adecuadas de abordaje y resolución.

Estas notas están basadas en la convicción de que la correcta implementación de un proyecto de intervención del Estado en la solución de carencias habitacionales críticas y masivas no consiste en "hacer más cantidad, más rápido, de lo mismo de siempre”, si se tienen en cuenta los resultados del más de medio siglo de costosas e inadecuadas políticas y estrategias habitacionales, sino en definir, producir y gestionar los modos de acción, las estructuras operativas y los instrumentos que permitan organizar la respuesta adecuada y duradera a la totalidad de la estructura del problema.

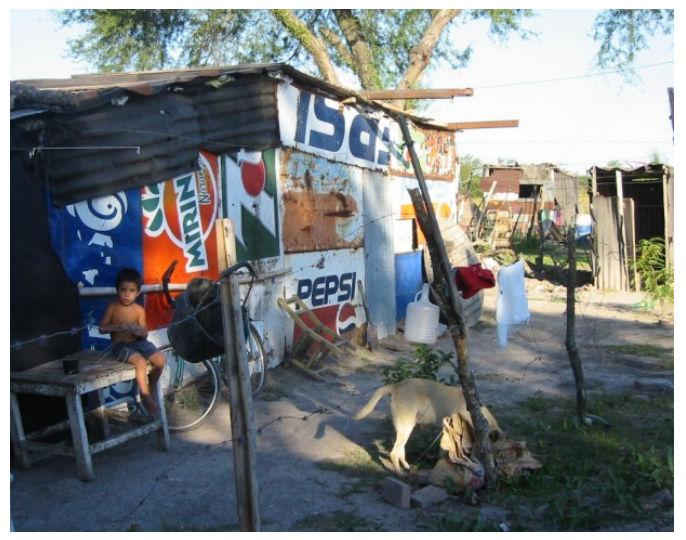

[izquierda] Figuras 1 y 2. Vivienda precaria en Resistencia, Chaco, Argentina. Fuente: V.S. Pelli.

[derecha] Figura 3. Vivienda precaria en Santa Fe, Argentina-el mercado de la precariedad. Fuente: V.S. Pelli.
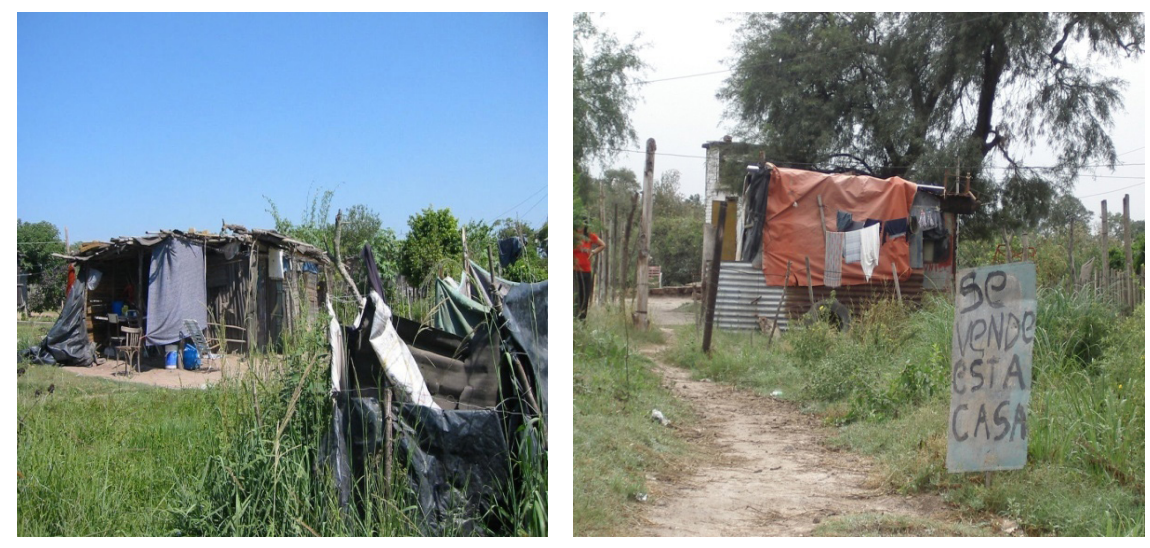

La pobreza en la América latina de fines del siglo xx y comienzos del xxi no es, en su mayor parte, la pobreza del trabajador oprimido y explotado, con salarios mínimos e insuficientes y condiciones degradantes de trabajo, que fue la imagen central del pensamiento y de los movimientos socio-políticos europeos de los siglos XIX y xx, y de sus prolongaciones en el área latinoamericana actual, sino la pobreza del hombre librado a su suerte, sin trabajo estructurado (a veces por varias generaciones) y sin conexiones sanas y suficientes con la sociedad consolidada en la que están solo físicamente insertados, ni formas de resolver mínimamente sus necesidades básicas según los códigos de esta sociedad solo con sus propios y escasos, o nulos, recursos y percepciones.

\section{La insuficiencia crónica de recursos de financiación}

En Argentina y en todos los países de la América latina los recursos presupuestarios asignados por la sociedad, a través del Estado, a la acción social de vivienda, son y han sido siempre insuficientes para eliminar el déficit habitacional crítico. Que no se trata, el déficit que debería im- 
portar, de cantidad de casas, sino de cantidad de grupos familiares con necesidades habitacionales críticas.

Puede discutirse si existe una auténtica insuficiencia presupuestaria en las cuentas del Estado o si se trata del resultado de decisiones políticas, explícitas o no, lícitas o no, conscientes en cuanto a sus consecuencias, o no. Es un tema básico de debate, pero que, aun en su criticidad, no es aconsejable instalar en términos de acción política en las mesas de trabajo donde se elaboran y gestionan casos concretos de solución habitacional. Allí, la insuficiencia de recursos funciona como un dato fijo del problema, instalado desde afuera y desde arriba. Pero esto no impide llevar el reclamo al escenario más amplio de la acción política por la construcción de la sociedad.

Esos cuatro rasgos de situación, con este magro basamento de insuficiencia financiera para abordarlos, son mojones de referencia para el diseño y la construcción de procesos de abordaje del problema. Ignorar la existencia de una estructura en la situación de carencia y desamparo suele resultar en acciones costosas y efectos dispersos, con los habituales resultados estereotipados e inadecuados frente al problema, o funcionales a otros objetivos ajenos al de la insatisfacción habitacional.

\section{El papel de la universidad}

Este panorama plantea compromisos y responsabilidades a un amplio reparto de actores sociales, cada uno con mayor o menor proximidad, poder de decisión, sensibilidad y creatividad. Uno de estos actores "externos", que merece considerarse básico y comprometido con este desafío, es la institución universitaria. Entre ella y las situaciones sociales en estado crítico hay un puente de posible intercambio, no siempre transitado: por un lado, el bagaje de saberes y recursos de las instituciones universitarias, y por otro, el abundante caudal de vivencias, conocimientos, capacidades y potencialidades de los sectores populares, no solo irreemplazable a la hora de definir y abordar sus propias necesidades y urgencias y recomendable en el momento de definir los satisfactores deseables para esas necesidades, sino también apto para enriquecer, con sabiduría fresca y con experiencias de trabajo inéditas, el acervo de la universidad.

En algunas universidades de Latinoamérica, no muchas, se viene desde hace décadas emprendiendo y desarrollando experiencias de clarificación y profundización teórica, de desarrollos de tecnologías apropiadas, de ejercitación de modelos de gestión a través de acciones de extensión universitaria, y de formación de profesionales adecuadamente orientados y capacitados, en un cuadro de contacto directo con la problemática habitacional, dentro de una situación general de carencia y exclusión. $\mathrm{O}$ con el sector popular en particular, con miras a aportar enfoques adecuados al abordaje de sus necesidades insatisfechas y también a su urgente necesidad de inserción y admisión como cabales ciudadanos en los mecanismos de intercambio, contacto y convivencia del conjunto social. Al final de esta presentación se expone el recorrido que, en busca de respuestas a estas inquietudes, hemos transitado, con algún logro y muchas tentativas insuficientes, en nuestra propia experiencia en una universidad latinoamericana.

Cuando la universidad opera con sus recursos frente a fenómenos poco conocidos desde su punto de observación, o con enfoques inno- 
vadores frente a fenómenos ya conocidos, se hace necesaria la adaptación y adecuación de sus propios mecanismos a las nuevas experiencias y a las nuevas construcciones conceptuales que puedan surgir de esta colaboración. Esto conduce a generar o adoptar nuevas estructuras de investigación-desarrollo, abrir nuevos mecanismos y nuevos canales para la extensión universitaria, y desarrollar nuevos paradigmas de perfil profesional, incluyendo el de los arquitectos, que es preciso que se encuentren motivados y entrenados para la integración de mesas interdisciplinarias e intersectoriales de decisión y gestión, en calidad de pares con otros tipos de actores, incluidos los habitantes.

\section{Criterios de abordaje: la discusión del modelo de gestión}

Es posible afirmar que no corresponde a la naturaleza del problema el criterio de instalar en el centro de atención y de desarrollo la calidad arquitectónica o el coste de la vivienda (la casa), aun sin dejar de prestarle suficiente atención; ni tampoco corresponde poner en el centro de atención el proceso de producción de la casa, si bien el incremento de la atención a los procesos por sobre la atención a la calidad aislada de la unidad-casa-prototipo históricamente ha sido y es visto como un avance. Más allá de este avance, la naturaleza del problema a resolver señala como centro de atención de la gestión habitacional al proceso de acceso a la situación habitacional aceptable.

\section{El servicio de acompañamiento y apoyo al acceso a la vivienda}

Merece atención, como respuesta adecuada a la estructura de situación expresada en aquellos cuatro indicadores, el concepto de servicio de acompañamiento y apoyo, que debería prestarse durante un extenso lapso, desde la preparación de los futuros habitantes para desarrollar una nueva forma de vida, pasando por la integración grupal y vecinal, por la integración de mesas de decisión y control del proceso de definición de prioridades y producción del ámbito habitacional, y por el control y manejo compartido de los fondos asignados para la producción de la solución habitacional; por la formación y encaminamiento de organizaciones vecinales y consorcios; por los procesos de aprendizaje de uso y mantenimiento de artefactos y materiales componentes del hábitat doméstico; por el manejo del presupuesto de mantenimiento de la vivienda; por las reglas de juego de las relaciones con el entorno urbano, en el nuevo contexto. Este programa de servicio aparece como garantía de que la acción desarrollada cumpla con su objetivo, satisfaga las necesidades de las personas correctas y garantice el destino correcto de los recursos asignados, durante lapsos extensos que aseguren la autenticidad y la permanencia de los resultados del servicio habitacional.

El proceso de acceso a la vivienda gestionado por medio de mesas de concertación intersectorial debe actuar como facilitador y colaborador en la transición desde la involuntaria y penosa cultura y economía de la pobreza y de la exclusión, hacia la plena integración en el conjunto social de contexto. Esto requiere adecuados tiempos de germinación y maduración. 
Nuestra experiencia de búsqueda, profundización teórica y práctica, y elaboración de modos de abordaje y resolución de la carencia habitacional crítica ${ }^{2}$

Dado el particular marco en que se ubica esta presentación, en este cuarto Congreso Arcadia, que hace expresa (y generosa) referencia a la propia trayectoria de este disertante y de sus grupos en su actividad institucional frente a este escenario, se ha decidido la presentación de los principales hitos de este trayecto de cincuenta años de desarrollo.

La experiencia cuyos principales rasgos se exponen a continuación ha sido un intenso y prolongado ejercicio de estudio teórico, de prueba y error, de plantear, adoptar y descartar caminos y formas de actuar, de sortear condiciones adversas o muy adversas de trabajo y de vida, y de arreglarse con lo que se tenía a mano: gente, habilidades, herramientas, recursos institucionales, eventos imprevistos. No es, por lo tanto, una clara puesta en práctica de los criterios expuestos hacia aquí, sino una ilustración del proceso de tareas teóricas y prácticas que han ido aportando a la construcción de esta estructura de gestión que se está proponiendo. Veamos:

\section{Hitos \\ 1967: Creación del Departamento de Diseño Arquitectónico, posteriormente Instituto de Investigación y Desarrollo en Vivienda, IIDVi}

En 1967 la Universidad del Nordeste (Argentina), a 10 años de su creación en un área geográfica que presentaba los más bajos indicadores socioeconómicos de Argentina, aprobó el proyecto de puesta en marcha de un centro de investigación-desarrollo en Arquitectura, orientado inicialmente a respaldar la docencia y la práctica profesional en esta profesión. ${ }^{3}$ Sin embargo, a poco de andar y de ampliar el conocimiento de la estructura social y habitacional local (tomada como testigo de una situación en términos generales similar a la de toda la región latinoamericana) y con las demandas y desafíos que esa realidad presentaba a la profesión y potencialmente a la universidad, tomamos la decisión de centrar la actividad en la problemática de las carencias habitacionales de los sectores sociales en situación de pobreza. La unidad recientemente creada pasó a ubicar su campo de trabajo, y más tarde su propia denominación, en la problemática de la gestión de la vivienda de acción social.

Desde las experiencias preliminares se hizo evidente que la tarea, por reflejo, exigía una revisión y ajuste de los modos de trabajo convencionales de una unidad universitaria y de exploración en un horizonte temático mucho más amplio que el de la vivienda en su acepción habitual y "tradicional".

Esto es lo que solemos entender como trabajo "hacia adentro". Hacia adentro de la profesión, hacia adentro del grupo y hacia adentro de la universidad. Las nociones básicas del oficio de arquitecto, en su imagen más convencional, o la de la relación del arquitecto con la problemática de la vivienda social, aparecían en un primer acercamiento como problemáticas y cuestionables frente a las reales exigencias del tema de trabajo y a los avances teóricos, externos ${ }^{4}$ y propios, sobre la naturaleza social y política del problema de las carencias de vivienda adecuada en los sectores populares.
2 Integrantes con actuación significativa en los diferentes equipos de trabajo de IIDVi, ICoHA, GDVP y/o MGDVS, en distintas épocas, desde 1967 hasta 2017. Por orden alfabético: Alcalá, Laura; Barreto, Miguel Ángel; Benítez, Andrea; Campos, Mariana; Cowper-Coles, Joan Rosemary; Dárdano, Carlos; Depettris, Nöel; Fernández, María Emilia; Franco, Rafael; Geraldo, Mabel; Giro, Marta; Gómez, Rubén; Melnechuk, Ramón; Lucca, Elena; Matta, Susana; Pace, Elizabeth; Pelli, María Bernabela; Romagnoli, Venettia; Rosso, Rubén; Schwartz, Rodolfo; Zieba, Antonio.

3 Las actividades de otros centros en la misma universidad dedicados a la exploración y extensión en otros campos, como agronomía, medicina regional, pueblos originarios, fueron una fuerte referencia para la aprobación de nuestra propuesta. 4 Entre las múltiples fuentes teóricas que desde un comienzo se estudiaron y se pusieron a prueba en la actividad del instituto, merece destacarse la obra de dos referentes: John Ch. Turner y Charles Abrams. 
Tanto en la elaboración teórica como en las experiencias prácticas se nos presentó como una contradicción el abordaje unidisciplinario de un problema que se iba mostrando como de carácter firmemente interdisciplinario, desde una Facultad de Arquitectura, dedicada a dos carreras: arquitectura y diseño gráfico, cada una de ellas con el perfil convencional de trabajo unidisciplinario. La solución de esa contradicción pasó a ser una línea más de preocupación y trabajo, no precisamente investigativa o de servicio, sino de gestión institucional: se han dedicado y se siguen dedicando actividades y esfuerzos a la promoción, dentro de la universidad, de unidades académicas pluridisciplinarias de abordaje de problemas complejos, abriendo además una puerta a la problemática del trabajo multisectorial, es decir, el trabajo con inclusión de actores no académicos ni profesionales, pero sí con fuerte presencia en el problema y en sus posibilidades de solución, principalmente los afectados por los problemas sobre los que se está trabajando.

En cuanto a nuestras propias posibilidades de respuesta, el instituto debió trabajar en sus primeros años con un equipo formado íntegramente por arquitectos, unos pocos, incluido el director, que está escribiendo esto. Pero las propuestas y los hallazgos que surgían de la tarea, y también del trabajo teórico en paralelo, reconocían la existencia de condicionantes e interrogantes que habrían requerido los enfoques de profesionales de otras disciplinas, como las del trabajo social, las ciencias sociales, las ciencias jurídicas, la economía, o la ingeniería de la construcción. En etapas posteriores se incorporaron al grupo en forma permanente profesionales del trabajo social, y las diversas situaciones de ensayo experimental de modelos de gestión permitieron contar para cada proyecto con ingenieros y contadores aportados por otras de las instituciones con intereses en los proyectos (organismos provinciales, municipios, empresas de servicios públicos).

Aquí se van a presentar, entonces, algunos de los proyectos más significativos de la historia de este grupo universitario de trabajo. No habrá una argumentación minuciosa de defensa y explicación de cada experiencia. No es el caso. Se pondrá el acento, en cambio, en el encuentro que se dio en cada paso, entre lo que se consideraba que se debía hacer, y lo que en los hechos se podía hacer. Esto, que aparecía de entrada como un inconveniente, en muchos casos funcionó como un aporte, o como un desafío cuya superación nos condujo a nuevos caminos para explorar (hacia afuera y hacia adentro).

\section{2: Sistema UNNE-UNO de vivienda núcleo}

Es el producto inicial de la actividad de desarrollo experimental. Aquí todavía el centro de la atención incluye un objeto arquitectónico, aunque en este caso se trata de un paquete conceptual en el que el objeto arquitectónico funciona como una pieza de un juego a completar, con intervención del habitante, con fuertes efectos de modificación del concepto de solución habitacional y como un aporte a una cobertura más extensa de los limitados recursos siempre insuficientes: atender a más destinatarios en su situación crítica con los mismos fondos disponibles, dejando puertas bien abiertas para el perfeccionamiento progresivo de la solución. La propuesta, si bien no ha sido nunca adoptada por los organismos oficiales de vivienda, como era previsible, tuvo una fuerte repercusión en los profesionales y estudiantes motivados 
por la situación política del momento en Argentina, que los encontraba sin herramientas adecuadas para ofrecer frente a los problemas de los sectores más desaventajados.
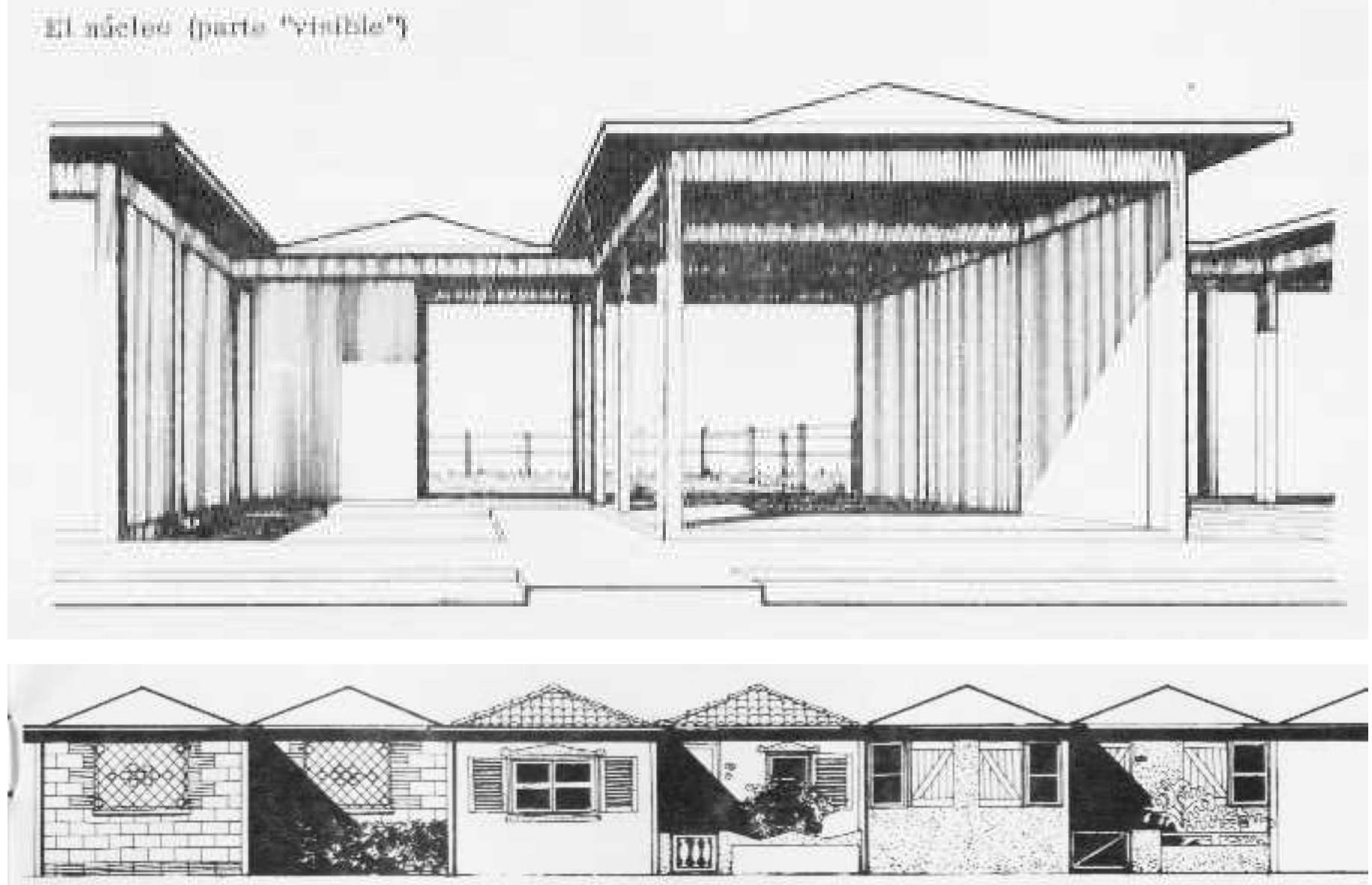

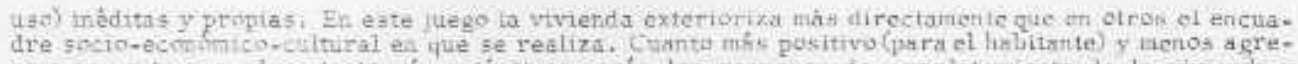
avo sea este encuadre, tainto más auténticos ferán log recureas de campletamiento de la vivisenda $y$

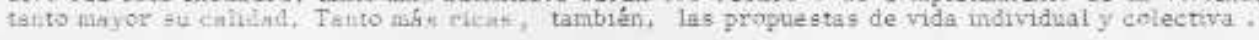

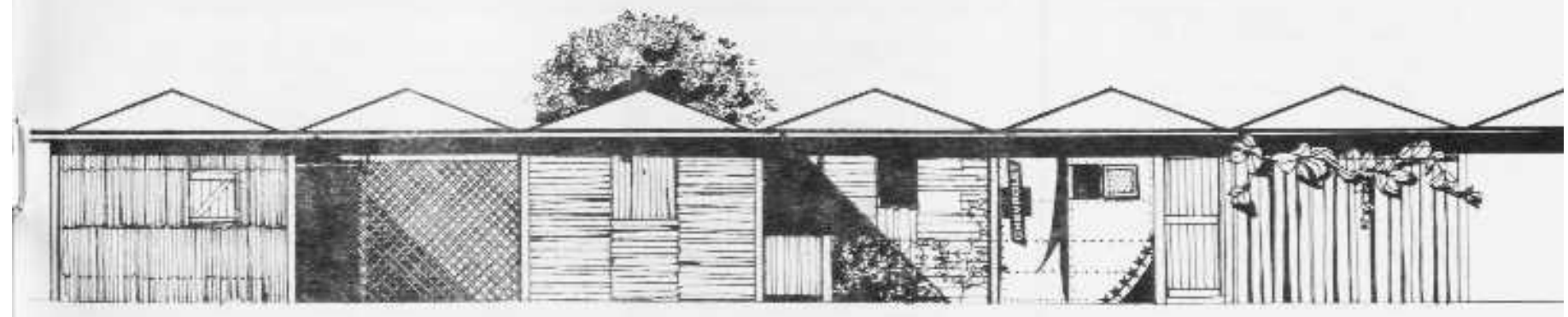

[arriba] Figura 4. Sistema UNNE-UNO de vivienda "nuclear"-la parte "visible". Fuente: Elaboración IIDVi.

[abajo] Figura 5. Sistema UNNE-UNO de vivienda "nuclear"-el habitante completa la vivienda básica con sus criterios y con sus recursos. Fuente: Elaboración IIDVi. 


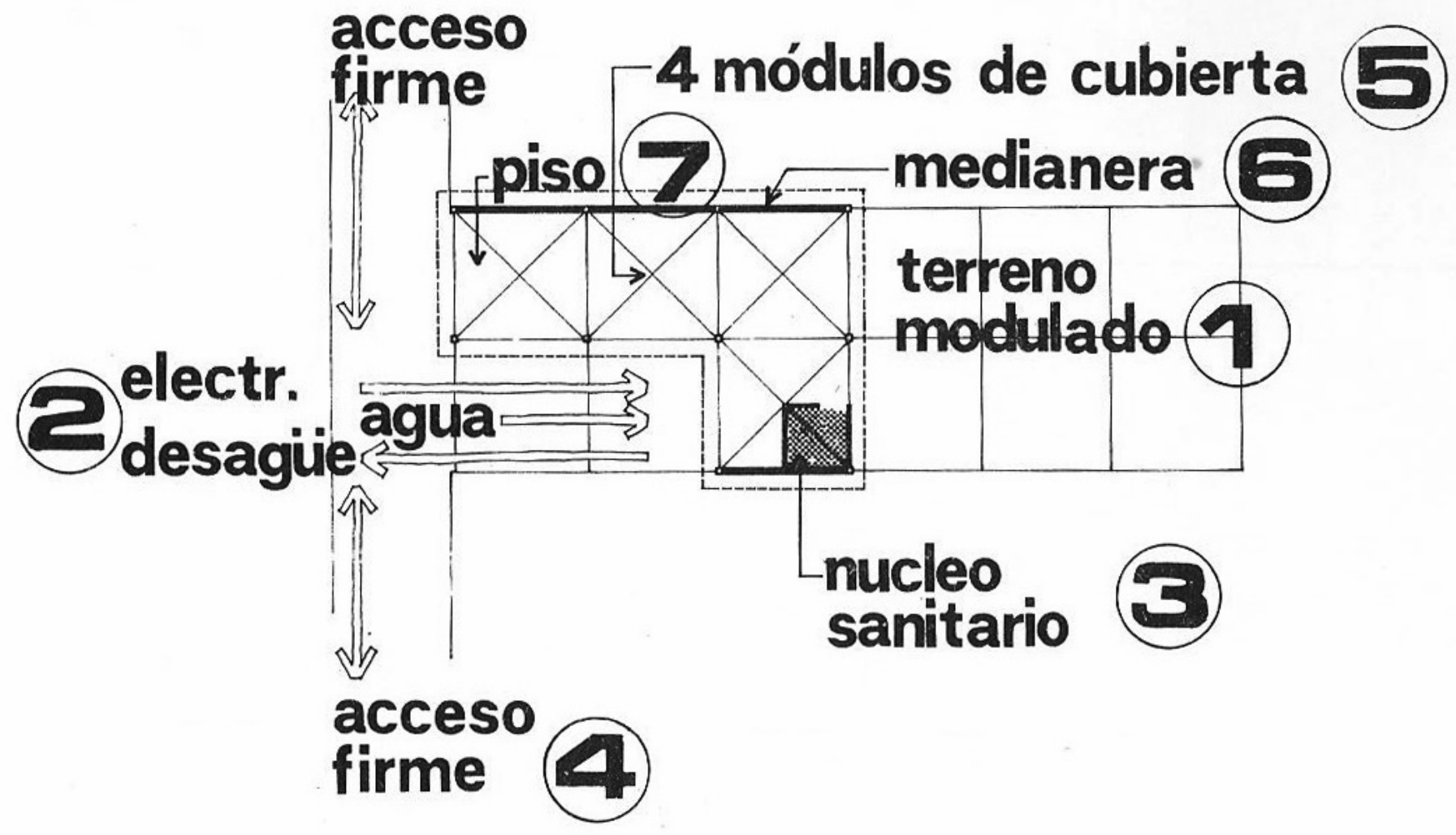

Figura 6. Sistema UNNE-UNO de vivienda "nuclear"-la inserción en redes como base de la solución habitacional. Fuente: Elaboración IIDVi.

Figura 7. Esquema operativo de Servicio de Techos UNNE-UNO. Fuente: Elaboración IIDVi.

\section{4: Servicio de techos}

En su enunciado básico esta propuesta se basa en un párrafo de Charles Abrams. Los moldes de acero con que se construyeron prototipos de la propuesta UNNE-UNO, y los pedidos de los operarios encargados de manejarlos, nos llevaron a idear un servicio a brindar por las municipalidades a los autoconstructores, que por otros canales se encuentran bregando por la propiedad de sus terrenos. Como experiencia de prueba lo implementamos, a manera de demostración, como un servicio de la universidad a través de nuestro Instituto.

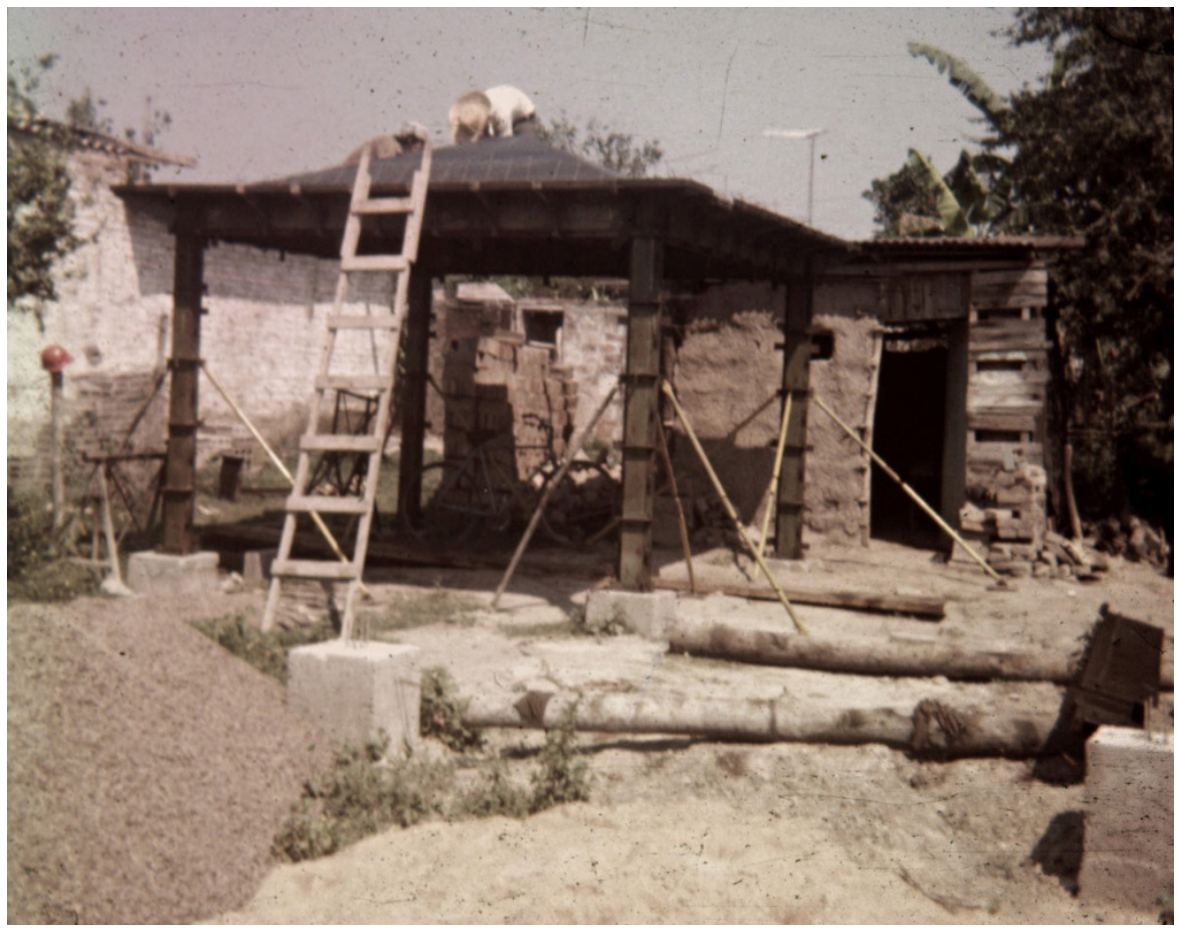




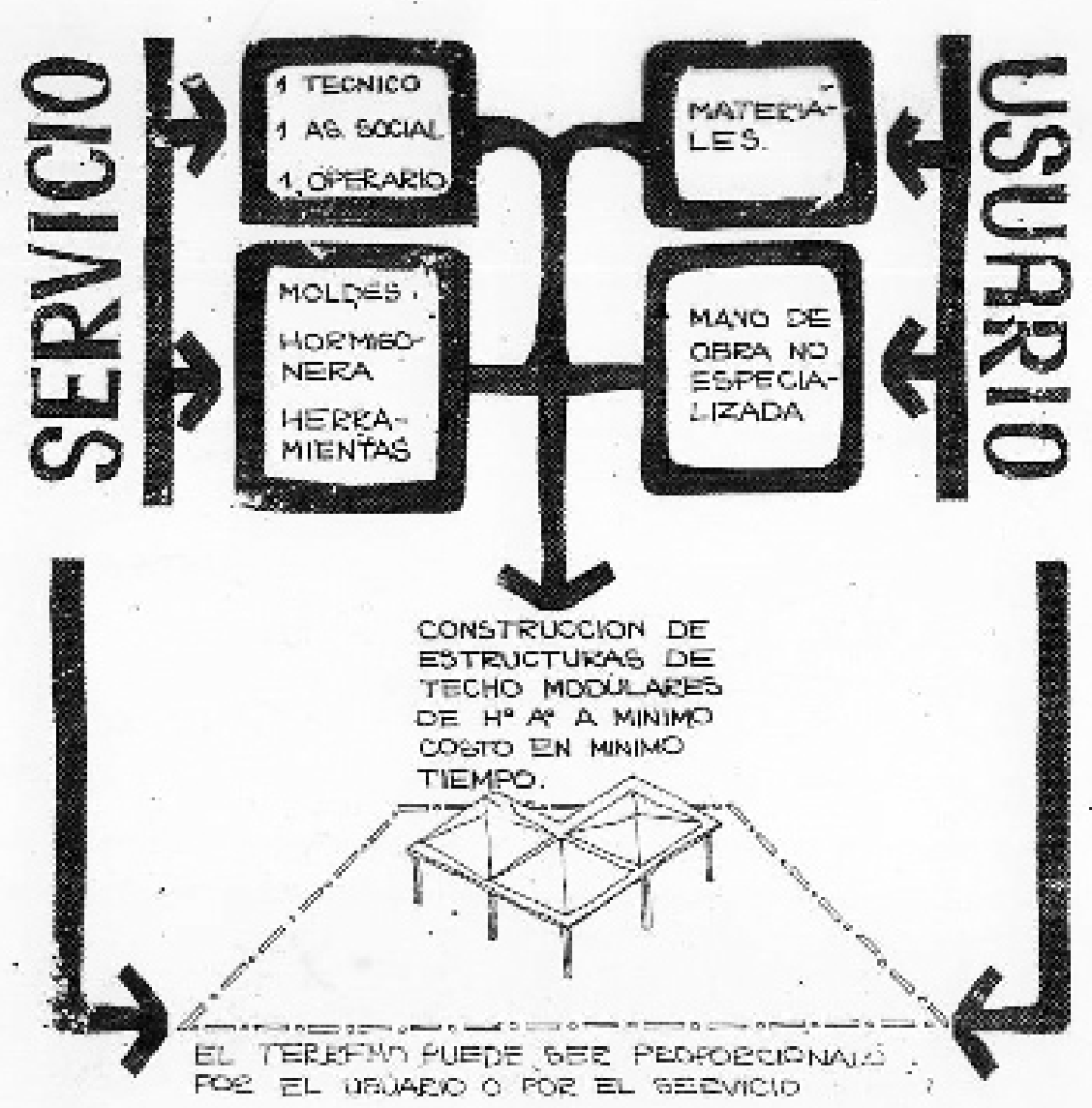

De todos modos, el Servicio de Techos, después de dos o tres casos, no pudo llegar a consolidarse ni como servicio universitario ni como servicio municipal, por la irrupción del Gobierno militar en 1976, del que hablamos más abajo.

\section{5: Consolidación del barrio Santa Catalina}

Un convenio con el Gobierno de la provincia nos puso en contacto con un conjunto de vecinos (220 familias) que pedían la propiedad y la regularización de los terrenos que estaban ocupando. Esta situación nos dio la posibilidad de avanzar en varios frentes temáticos: internarnos en el trabajo intensamente participativo de escala barrial urbana, trabajar en base a una estructura urbana preexistente, abriendo camino al mejoramiento de la situación habitacional. La consolidación (o el mejoramiento, para emplear la expresión más divulgada) de asentamientos irregulares es una modalidad de abordaje que a mediados de los años setenta recién estaba siendo asimilada por las oficinas técnicas de algunos gobiernos latinoamericanos.

También el proyecto Santa Catalina debió interrumpirse por la irrupción del Gobierno de facto de las juntas militares. Pero en este caso las etapas que se lograron concretar fueron suficientes para modificar en profundidad la estructura del barrio y para reforzar el trabajo comunitario.
Figura 8. Ampliación de una vivienda por autoconstrucción con los moldes del Servicio de Techos. Fuente: V.S. Pelli. 


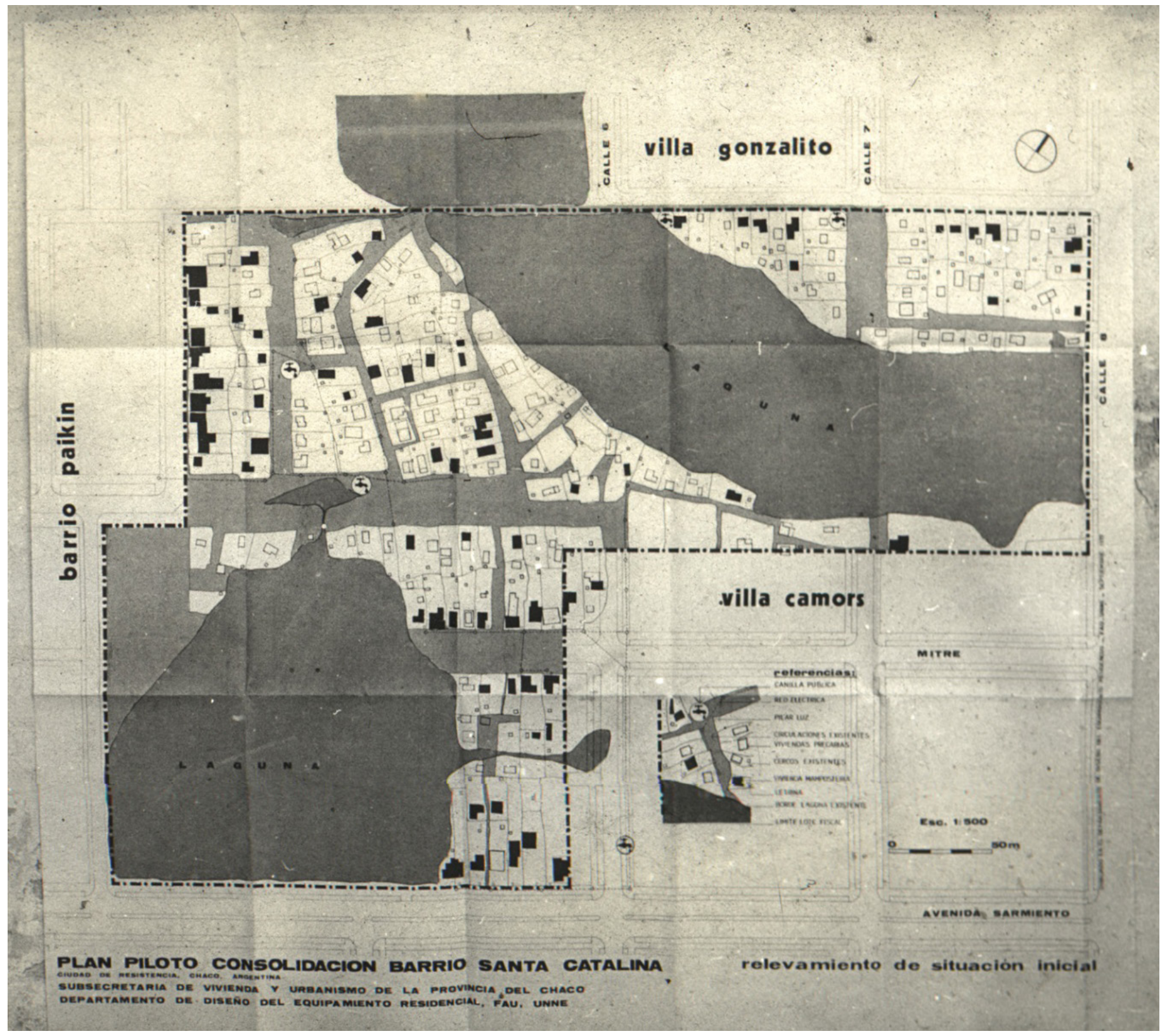

[arriba] Figura 9. Proyecto de Consolidación del barrio Santa Catalina (Resistencia Chaco, Argentina). Situación inicial, 1975 Fuente: Elaboración IIDVi.

[derecha] Figura 10. Proyecto de Consolidación del barrio Santa Catalina-Superposición de situación inicial con propuesta de trazado definitivo. Fuente: Elaboración IIDVi.

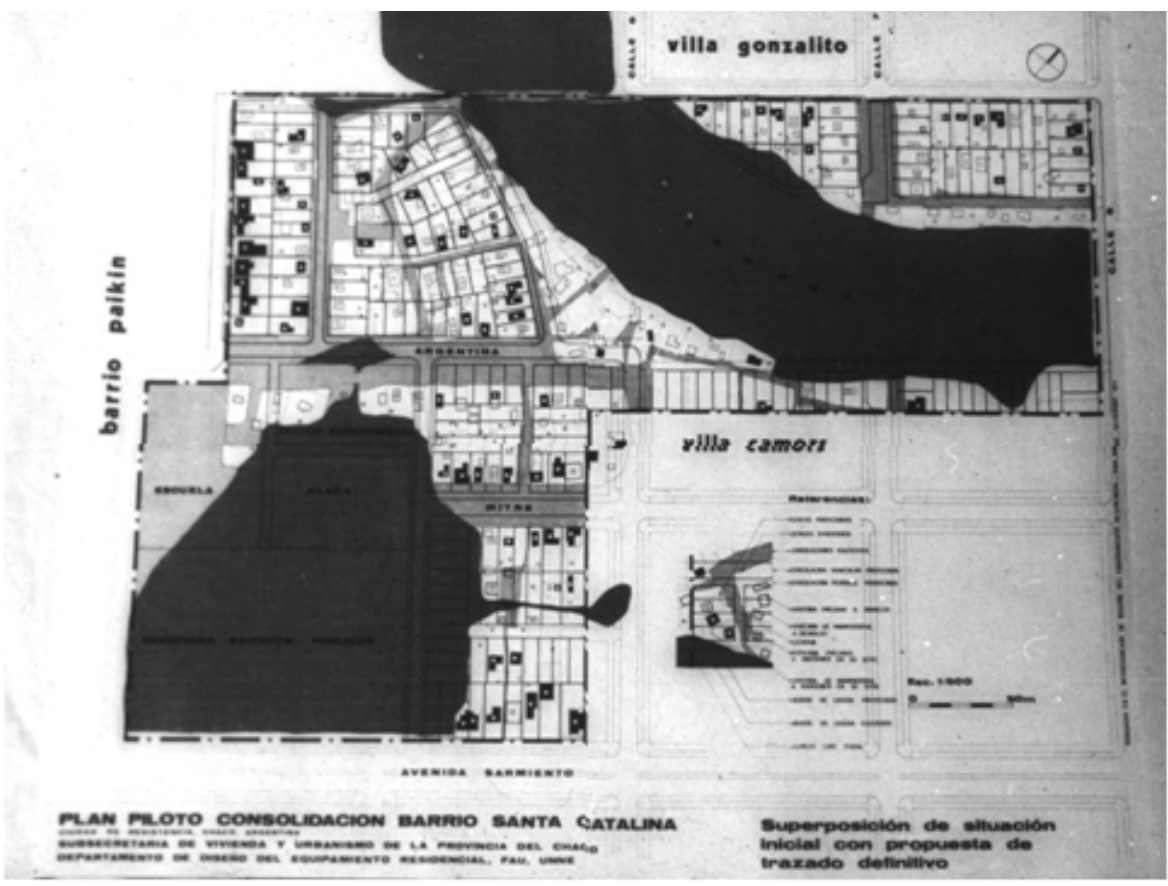




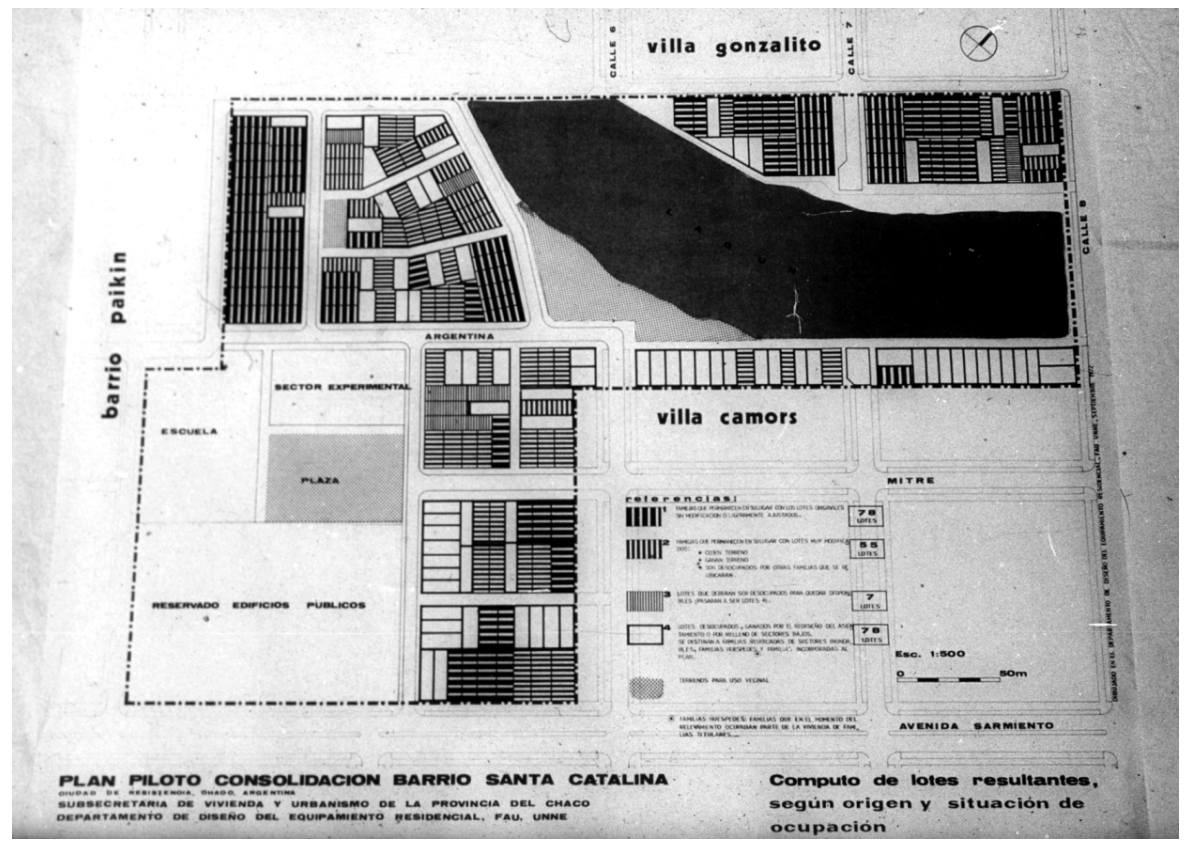

[izquierda] Figura 11. Proyecto de Consolidación del barrio Santa Catalina-Tipos de lotes resultantes, según origen y situación de ocupación. Fuente: Elaboración IIDVi. [abajo] Figura 12. Proyecto de Consolidación del barrio Santa Catalina-planilla de ubicación de módulos-techo en los lotes regularizados. Fuente: Elaboración IIDVi.

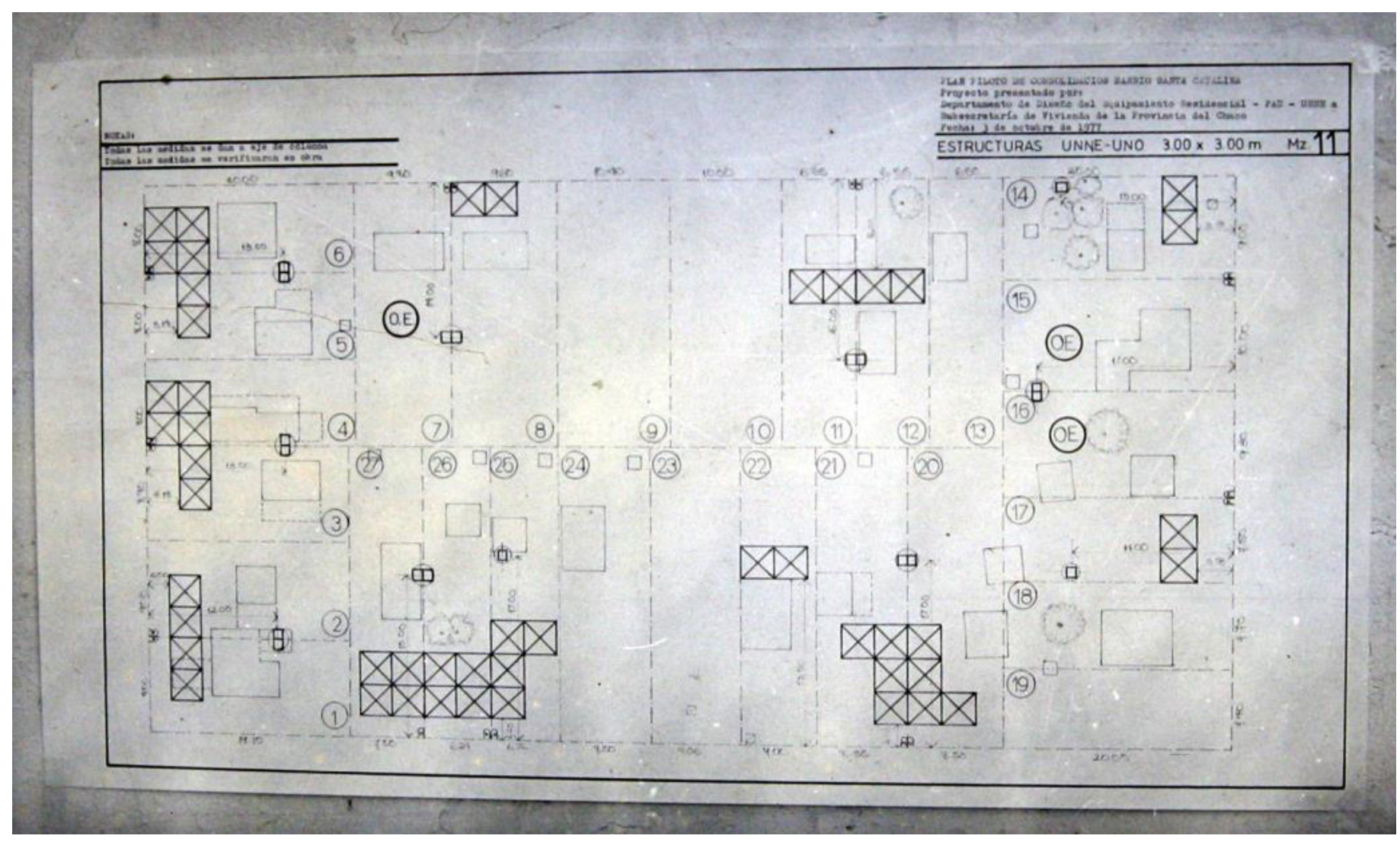




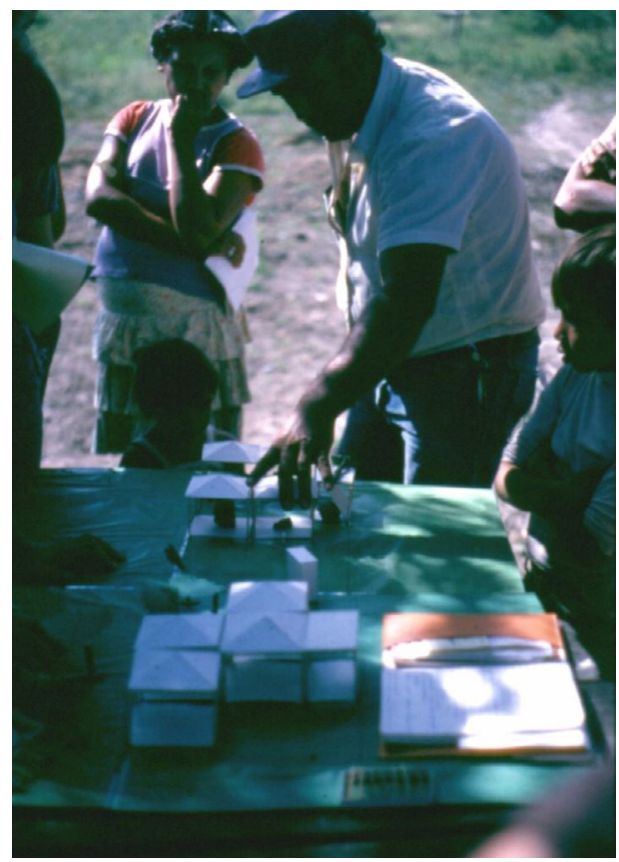

[izquierda] Figura 13. Proyecto de Consolidación del barrio Cacique Pelayo.

Diseño participativo y grupal; acuerdos entre vecinos. Fuente: ICoHa.

[derecha] Figura 14. Proyecto de Consolidación del barrio Santa Catalina: los módulos de estructura y cubierta se incorporan al proceso de autoconstrucción.

Fuente: Elaboración IIDVi.

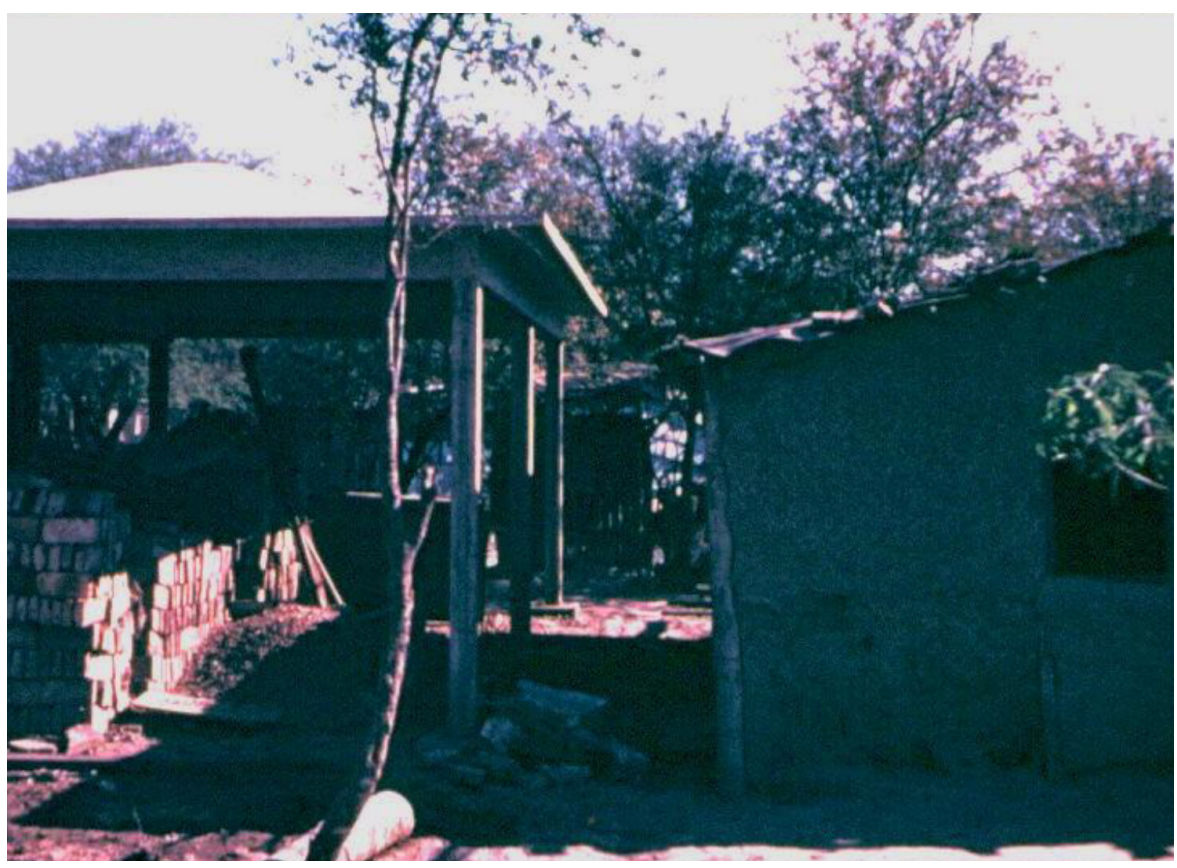

1976-1983

En el período de vigencia del Gobierno de las juntas militares no hubo casos extremos de daño a miembros del equipo, pero de una $\mathrm{u}$ otra manera la conmoción general y las presiones institucionales provocaron la dispersión del grupo, que quedó reducido a su director y una integrante, que nos dedicamos a cumplir actividades docentes convencionales y a preservar el espacio institucional, la existencia y la conducción del Instituto.

\section{6-2001: $\mathrm{ICoHa}{ }^{5}$}

Como un ejemplo de la idea de trabajar simultáneamente "hacia afuera", hacia el problema a resolver, y "hacia adentro", hacia nuestra propia capacidad de trabajo, decidimos crear una organización no gubernamental que nos permitiera actuar con mayor agilidad que la que permitían las estructuras y los modos de gestión de la universidad. La organización se denominó Instituto para la Comunidad y el Hábitat. El ICoHa no reemplazó al IIIDVi como marco de nuestras experiencias: más bien abrió nuevas puertas de contacto entre las instituciones y asociaciones externas y la administración propia de la Universidad. Los sellos institucionales funcionaron alternativamente según las circunstancias a resolver. Merece acotarse que, por el convenio oficialmente establecido con la universidad, esta compartía la autoría intelectual de lo que se iba encontrando o desarrollando a través de ICoHa. ICoHa fue el resultado de un ajuste "hacia adentro": un perfeccionamiento de nuestra estructura institucional y un paso firme de avance en la clarificación de un modo de gestión. La actividad a través de la figura del ICoHa se mantuvo en vigencia desde 1986 hasta 2001.

5 El ICoHa estuvo en actividad hasta 2001. A partir de ese año se mantiene su existencia jurídico-institucional, pero ha suspendido sus actividades de elaboración y servicio. 
1987: GDVP-Gestión y Desarrollo de la Vivienda Popular, asignatura electiva en el penúltimo año de la Carrera de

Arquitectura [2008: obligatoria para todos los estudiantes de la carrera de Arquitectura]

Esta iniciativa también es respuesta a la consigna de "trabajo hacia adentro", aunque en este caso no se trataba tanto de mejorar o ampliar las capacidades de nuestro propio grupo, sino de definir la formación del arquitecto capacitado para hacerse cargo de las consignas de trabajo que se han expuesto en esta presentación. Ciertamente, una experiencia de un año en una carrera que, de hecho, está íntegramente estructurada para la formación convencional del arquitecto, con mayor acento en la creación de "edificios-objeto", no es suficiente para poner en escena la imagen del arquitecto en equipos de solución de carencias habitacionales, interdisciplinarios o intersectoriales. Pero la devolución hecha por los estudiantes sobre esta experiencia señaló un impacto en general y una indicación de caminos para los que ya estaban predispuestos.

GDVP fue la primera asignatura en carreras de Arquitectura de Argentina que llegó a incluirse con carácter permanente en el plan de estudios. Funcionó como asignatura electiva hasta 2008, año en que pasó a ser obligatoria para todos los estudiantes de la carrera, sin debilitamiento de la formación convencional.

\section{3: Regularización urbana del asentamiento de pueblos}

originarios Cacique Pelayo, en el Municipio de Fontana, en el Gran

Resistencia

Un asentamiento sobre unas vías de ferrocarril abandonadas, de unas 220 familias, de las cuales aproximadamente 200 pertenecían a la etnia Q'om o Toba. El problema presentaba aspectos particulares, como el de la necesidad de solución de serios problemas de drenaje de suelos, o la posibilidad de organizar mesas de concertación con los habitantes, el equipo técnico de IIDVi-ICoHa y representantes de los organismos nacionales, provinciales y municipales. El equipo técnico de IIDVi-ICoHa debió prestar especial atención a los problemas de comunicación y entendimiento con la estructura cultural de los habitantes.
Figura 15. Proyecto de Consolidación del barrio Cacique Pelayo-rediseño participativo y concertado-situación inicial. Fuente: Elaboración IIDVi-ICoHa.

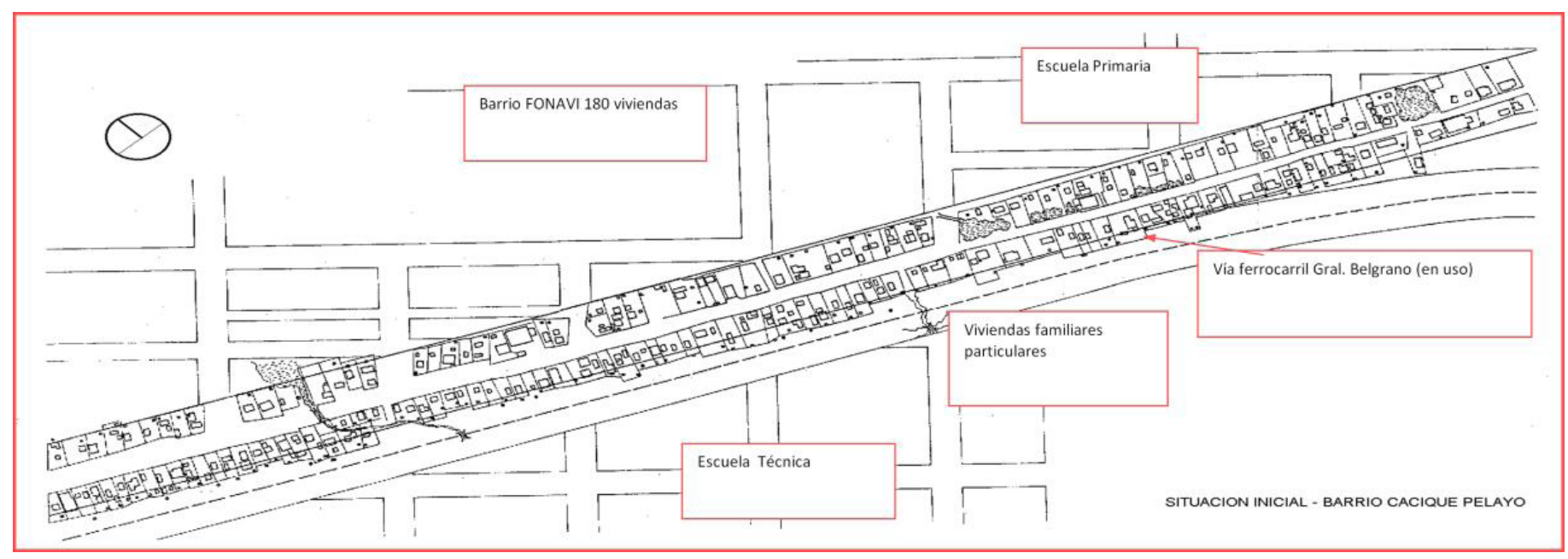




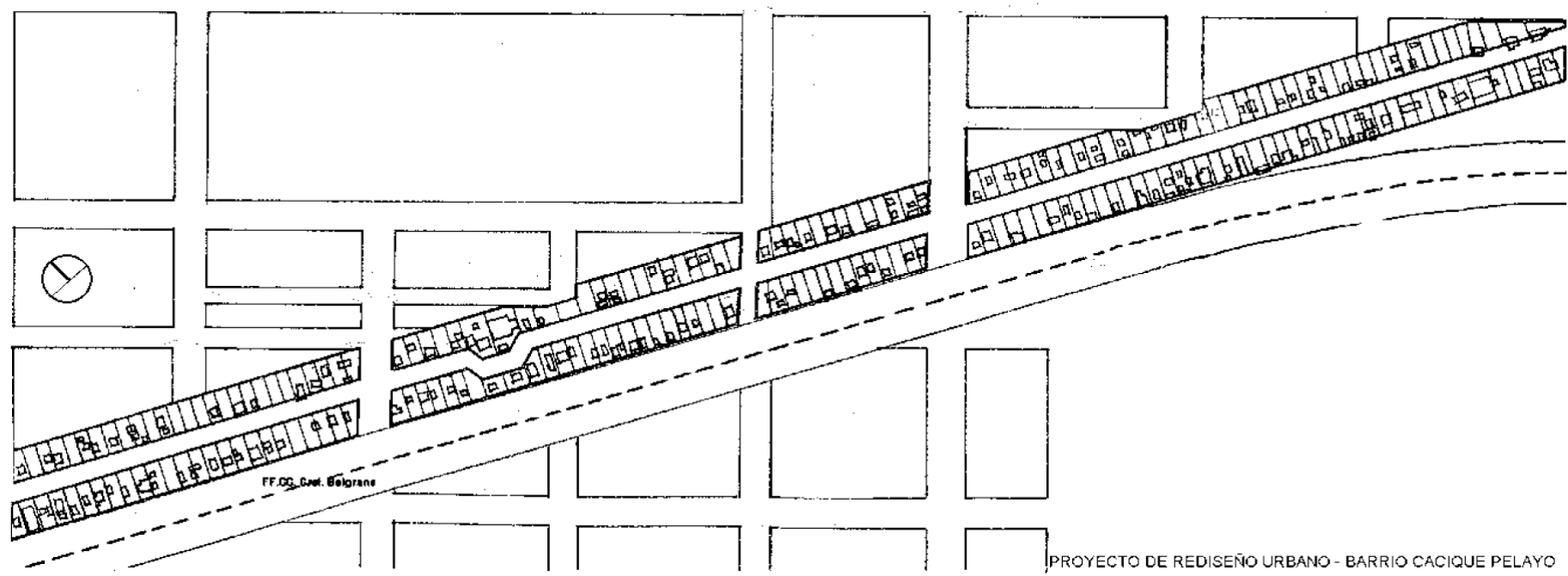

[arriba] Figura 16. Proyecto de Consolidación del barrio Cacique Pelayo-propuesta de rediseño, participativa y concertada. Fuente: Elaboración IIDVi-ICoHa.

[abajo] Figura 17. Proyecto de Consolidación del barrio Cacique Pelayo-reunión comunitaria con asistencia de grupo técnico. Fuente: IIDVi-ICoHa.

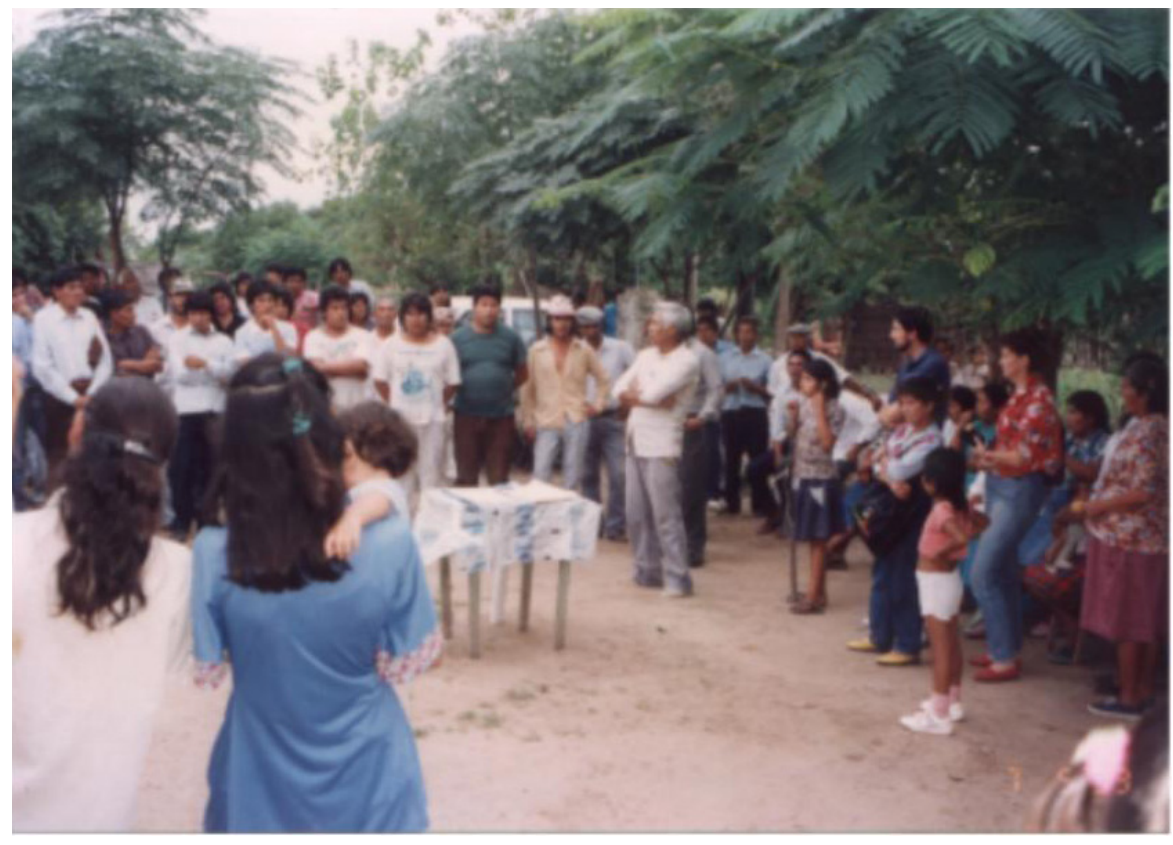

1995: Cinco barrios. Convenio con UNICEF Argentina

Fueron tres proyectos sucesivos, en un sector urbano de considerable extensión, que avanzaron sobre el problema del agua potable, desde la instalación de cañerías, y luego de unidades sanitarias (baños), con una red cloacal alternativa, de funcionamiento controlado por los vecinos. Trabajo integral de rediseño y ajuste del trazado urbano y de la subdivisión en lotes. Tareas de ingeniería de regularización de situaciones anegables; desagotes. El trabajo se realizó en torno a la mesa de concertación, con representantes de los habitantes, de UNICEF y de los diversos organismos nacionales, provinciales y municipales involucrados.

\section{3: MGDVS: Maestría en Gestión y Desarrollo de la Vivienda} Social

La experiencia con la asignatura de grado señaló al grupo la posibilidad de poner en marcha una instancia de formación de posgrado. En este caso se trataba de enriquecer la formación de los egresados que es- 

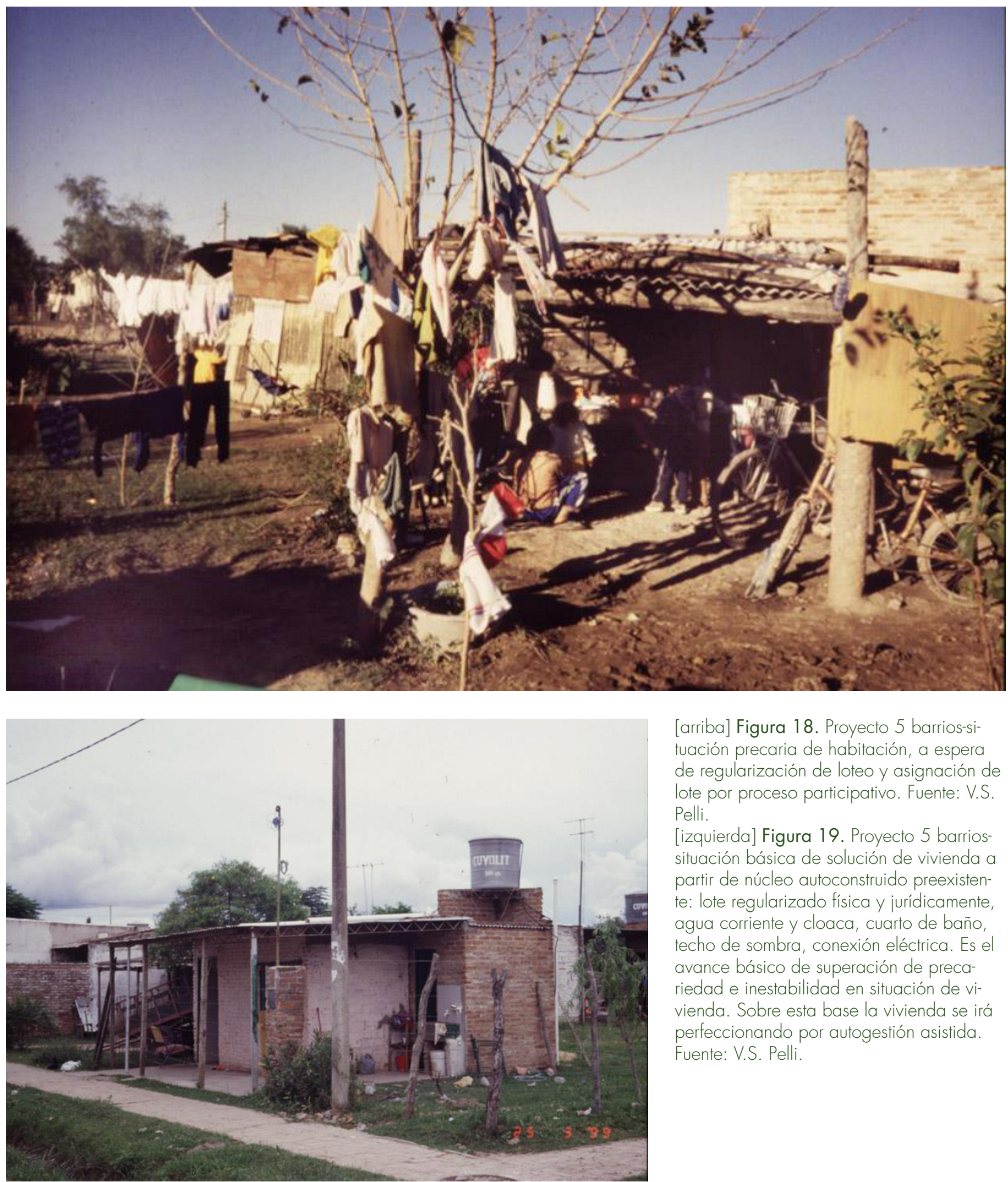

[arriba] Figura 18. Proyecto 5 barrios-situación precaria de habitación, a espera de regularización de loteo y asignación de lote por proceso participativo. Fuente: V.S. Pelli.

[izquierda] Figura 19. Proyecto 5 barriossituación básica de solución de vivienda a partir de núcleo autoconstruido preexistente: lote regularizado física y jurídicamente, agua corriente y cloaca, cuarto de baño, techo de sombra, conexión eléctrica. Es el avance básico de superación de precariedad e inestabilidad en situación de vivienda. Sobre esta base la vivienda se irá perfeccionando por autogestión asistida. Fuente: V.S. Pelli.

taban (y están) trabajando como técnicos en organismos de los estados provinciales de la región. Y también para los que, desde los mismos ámbitos académicos, buscaban perfeccionar sus contactos con el tema habitacional. La condición de curso de posgrado permitió abrir la cobertura disciplinaria hasta lograr un panorama pluridisciplinario en el conjunto de profesores disertantes, en la calificación profesional de los cursantes (arquitectos y trabajadores sociales) y en los temas a desarrollar. 
Las Redes

En el desarrollo del grupo y del proyecto general jugó un papel importante la pertenencia a redes de cobertura latinoamericana. Esta experiencia permitió hacer contacto con los técnicos y visitar los centros de toda la región. Esto produjo un enriquecimiento irreemplazable para la tarea propia y para la apertura de horizontes. Corresponde mencionar al Subprograma de tecnología para la vivienda de interés social (HABYTED) integrante del Programa CYTED, Ciencia y técnica para el Desarrollo, sostenida por los organismos de Ciencia y Tecnología de toda la región, con el aporte y el estímulo de la Cooperación Española. Por otro lado, la Red ULACAV, Red Universitaria Latinoamericana de Cátedras de Vivienda, que hasta el día de hoy propicia el contacto, el intercambio y el apoyo mutuo entre cátedras de la región. Nuestro grupo universitario ha tenido una presencia activa en las dos instancias.

\section{El perfil del arquitecto en la mesa de concertación del servicio de apoyo al proceso de acceso a la vivienda}

En el modo de trabajo en grupos multidisciplinarios o multisectoriales, el arquitecto se encuentra con nuevas consignas para su gestión y su valoración profesional:

- El contacto con los habitantes, persona a persona, como modalidad de servicio profesional. No se trata solo de adoptar actitudes individuales, sino también de desarrollar estructuras de gestión que posibiliten y se enriquezcan con esta modalidad de trabajo;

- El diseño de procesos con equivalente jerarquía, pertinencia y atención que el diseño de objetos;

- La tecnología apropiada y apropiable. Pueden ser soluciones de tecnología "punta", pero también pueden ser recursos de la tecnología convencional, la del "negocio de materiales de obra de la vuelta de la esquina", lo que mejor responda a las circunstancias de producción, costos, cultura de uso y mantenimiento;

- La tecnología "dura" y la tecnología "blanda". Puede entenderse como "tecnología blanda" a los instrumentos y a los condicionantes legales, contractuales, reglamentarios y didácticos en la estructura de gestación y de producción de un proceso de acceso a la vivienda;

- El arquitecto actor (del proceso de solución compartido con otros actores) en lugar del arquitecto autor (de la solución arquitectónica o arquitectónico-urbanística);

- La negociación entre la estética del habitante y la estética del arquitecto. Esta consigna, de relativamente fácil implementación en las transacciones entre arquitecto, comitente y usuario cuando todos estos personajes se ubican en un mismo estrato sociocultural, requiere una particular actitud de comunicación y respeto entre arquitecto y usuario, cuando se trata de trabajar para/ con sectores en situación de pobreza y marginación;

- El trabajo intersectorial en la gestación y en la gestión de los procesos (la gestión compartida por los profesionales con los habitantes, y con representantes de otros sectores interesados, comprometidos y/o afectados); 
- El ajuste de las motivaciones y consignas del arquitecto: modo y estilo de vida, nociones de éxito y de fracaso profesional y/o personal.

En nuestra experiencia, ser arquitecto y ser universidad frente a demandas críticas de la sociedad no significó abandonar la profesión ni las funciones académicas. Significó elaborar y recorrer una vía atípica para el ejercicio de la profesión, en atención a las originales condiciones en que se plantea el problema a enfrentar y resolver.

Y la universidad, en nuestra experiencia, nunca ha dejado de ser universidad: más bien puede decirse que ha encontrado nuevas vías para enriquecer su caudal de conocimiento, de actitudes y de potencialidades. Y de genuino prestigio en su medio de implantación.

Pelli, V. (2017). La pobreza, la universidad y el oficio de arquitecto en la América latina de comienzos del siglo xxi. Hábitat y Sociedad, 10, 305-322.

<http://dx.doi.org/10.12795/HabitatySociedad.2017.i10.17> 


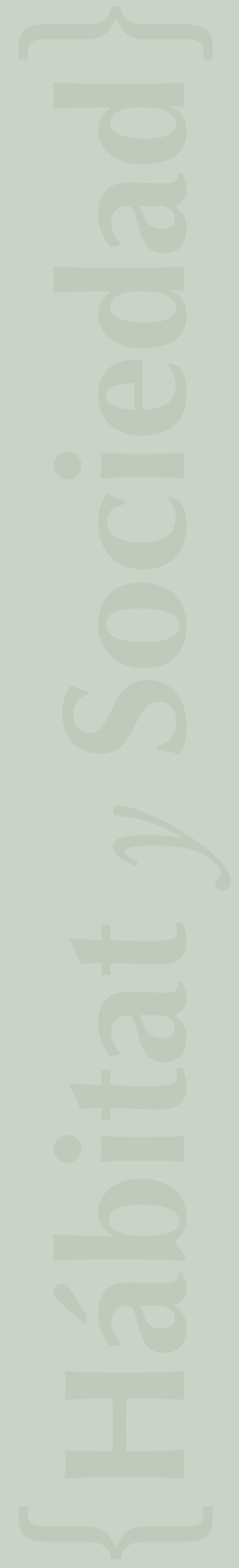

